\title{
Article \\ Vibration Perception Thresholds of Skin Mechanoreceptors Are Influenced by Different Contact Forces
}

\author{
Claudio Zippenfennig*(D), Bert Wynands and Thomas L. Milani
}

check for updates

Citation: Zippenfennig, C.;

Wynands, B.; Milani, T.L. Vibration

Perception Thresholds of Skin

Mechanoreceptors Are Influenced by

Different Contact Forces. J. Clin. Med.

2021, 10, 3083. https://doi.org/

$10.3390 / \mathrm{jcm} 10143083$

Academic Editor: José A. Vega

Received: 29 May 2021

Accepted: 11 July 2021

Published: 13 July 2021

Publisher's Note: MDPI stays neutral with regard to jurisdictional claims in published maps and institutional affiliations.

Copyright: (c) 2021 by the authors. Licensee MDPI, Basel, Switzerland. This article is an open access article distributed under the terms and conditions of the Creative Commons Attribution (CC BY) license (https:/ / creativecommons.org/licenses/by/ $4.0 /)$.
Department of Human Locomotion, Faculty of Behavioral and Social Sciences, Institute of Human Movement Science and Health, Chemnitz University of Technology, 09107 Chemnitz, Germany; bert.wynands@hsw.tu-chemnitz.de (B.W.); thomas.milani@hsw.tu-chemnitz.de (T.L.M.)

* Correspondence: claudio.zippenfennig@hsw.tu-chemnitz.de; Tel.: +49-371-531-34467
Abstract: Determining vibration perception thresholds (VPT) is a central concern of clinical research and science to assess the somatosensory capacity of humans. The response of different mechanoreceptors to an increasing contact force has rarely been studied. We hypothesize that increasing contact force leads to a decrease in VPTs of fast-adapting mechanoreceptors in the sole of the human foot. VPTs of 10 healthy subjects were measured at $30 \mathrm{~Hz}$ and $200 \mathrm{~Hz}$ at the heel of the right foot using a vibration exciter. Contact forces were adjusted precisely between $0.3 \mathrm{~N}-9.6 \mathrm{~N}$ through an integrated force sensor. Significant main effects were found for frequency and contact force. Furthermore, there was a significant interaction for frequency and contact force, meaning that the influence of an increasing contact force was more obvious for the $30 \mathrm{~Hz}$ condition. We presume that the principles of contrast enhancement and spatial summation are valid in Meissner and Pacinian corpuscles, respectively. In addition to spatial summation, we presume an effect on Pacinian corpuscles due to their presence in the periosteum or interosseous membrane.

Keywords: vibration perception threshold; mechanoreceptors; sensory perception; spatial summation; Meissner and Pacinian corpuscles

\section{Introduction}

Mechanoreceptors in the skin of human feet provide important information about various environmental stimuli [1]. If this feedback system fails, e.g., due to diseases such as diabetes mellitus or Parkinson's disease, gait and balance often deteriorate [2,3]. It is therefore a central concern of clinical research and science to assess the somatosensory capacity of humans, as a decrease in sensitivity may be an early sign of peripheral neuropathy [4].

Four different types of cutaneous mechanoreceptors are responsible for sensing and transmitting diverse pressures and vibrations at the sole of the foot: slowly adapting (SA) type I (Merkel discs) and II (Ruffini corpuscles) receptors, which react to continuous pressure, and fast-adapting (FA) type I (Meissner corpuscles) and II (Pacinian corpuscles) receptors, which respond to the onset and offset of stimulation. SA I and FA I receptors are located near the skin surface and have small and well-defined receptive fields. SA II and FA II receptors lie deeper in the skin and have large receptive fields with obscure boundaries [5,6]. In this study, we focused on Meissner (FA I) and Pacinian (FA II) corpuscles.

Determining vibration perception thresholds (VPT) is a form of quantitative sensory testing. To produce reliable results, it is essential to standardize procedures. Numerous influencing factors for determining VPTs have already been studied. These include frequency [6-8], anatomical location [8], size of the probe [9,10], mechanical skin properties [1,11], temperature [12], gender [13], and age [14]. One parameter that has received little attention to date is the quantity of the load (pressure, acceleration, and contact area) with which the indenting object stresses the corresponding area of the subject's skin.

Over the last 15 years, research studies measuring VPTs have used different contact forces, ranging from no force offset to avoid pre-activation of mechanoreceptors before 
the vibration stimulus [8], a preload of $2 \mathrm{~N}$ [11], and a preload of $4 \mathrm{~N}$ to simulate the pressure under the foot during walking [15]. These different contact forces may restrict the comparison of VPTs, since different studies have shown that increasing preloads from 0.1 $\mathrm{N}$ up to $8 \mathrm{~N}$ leads to an improvement in sensitivity [16-18]. In contrast, Hagander et al. [19] found decreased sensitivity at preloads of $1 \mathrm{~N}$ compared to $0.3 \mathrm{~N}$ and $0.5 \mathrm{~N}$ at the index finger. At the big toe, increasing preloads had no influence on VPTs [19]. Furthermore, Gregg [20] and Era and Hänninen [21] confirmed the results of Hagander et al. [19] at the big toe, finding no dependence between different contact forces and VPT. Two recently published studies evaluated the influence of standing compared to sitting while measuring VPTs at the sole of the foot [22,23]. Interestingly, these two studies also had contradictory results. While Mildren et al. [22] partially found a significant increase of VPT while standing in comparison to sitting, Germano et al. [23] found no significant differences. As both studies showed higher contact forces when standing compared to sitting, these two studies reflect the contradictions in the current literature.

To our knowledge, only Gu and Griffin [24] have examined the influence of different contact forces on VPT at the sole of the foot [24]. Their results exhibit slight VPT decreases with increasing force at the hallux and the ball of the foot. VPT decreases were more pronounced at $160 \mathrm{~Hz}$ than at $20 \mathrm{~Hz}$ [24]. In contrast to Gu and Griffin [24], our study did not use a static probe surrounding, which would compress the skin around the probe as well. Instead, only the vibrating probe exerted the contact force. A wide range of contact forces $(0.3-9.6 \mathrm{~N})$ was examined, exceeding typically-used values $(0-4 \mathrm{~N})$ in previous studies $[8,11,15]$, to detect possible ceiling effects. To evaluate the effect on Meissner and Pacinian corpuscles separately, VPTs were collected at the most sensitive frequency of each receptor type. We hypothesized that increasing contact forces leads to a decrease in VPTs at both mechanoreceptors, which results in improved foot sensitivity. Finally, we tested the hypothesis that there is an interaction between sensor type and increasing contact forces.

\section{Materials and Methods}

Ten healthy young subjects participated in this study $\left(8 \sigma^{7} / 2\right.$ \%; mean \pm SD: $22.9 \pm 1.4$ years, $74.9 \pm 9.7 \mathrm{~kg}, 178.8 \pm 9.7 \mathrm{~cm}$ ). All participants gave their written consent and were free of any diseases that could affect the sensory system (diabetes mellitus, peripheral neuropathy, neurological diseases, etc.). All procedures were performed in accordance with the recommendations of the Declaration of Helsinki. The measurement system and methodology were approved by the Ethics Committee of the Faculty of Behavioural and Social Sciences of the corresponding university for a similar study in our work group (V-277-17-DS-KUS/WUS-22062018) [25]. The sensory measuring procedure has been validated and used in several published studies $[1,23,26]$.

A modified vibration exciter (Typ 4180, Brüel \& Kjaer Vibro GmbH, Darmstadt, Germany) powered by a powerbank (XTPower MP-3200, Batteries and Power Solutions GmbH, Ellwangen, Germany) was used to measure VPTs (Figure 1). To exclude mechanical influencing factors, the vibration amplitude $(\mu \mathrm{m})$ was calculated using an external acceleration sensor (MMA2240KEG, NXP Semiconductors Netherlands B.V., Eindhoven, The Netherlands) placed in series with the probe of the vibration exciter (Figure 1). To measure the vibration amplitude as accurately as possible, the vertical movement of the vibration exciter's probe (diameter $7.8 \mathrm{~mm}$ ) was calibrated before the measurements using a highprecision capacitive position sensor (CS05, Micro-Epsilon Messtechnik GmbH \& Co. KG, Ortenburg, Germany). This ensured direct readings of the vibration amplitude during VPT measurements. Using a swivel arm, the probe of the vibration exciter was placed precisely perpendicularly at the plantar heel. A force sensor (DS050A9, disynet GmbH, BrüggenBracht, Germany), also placed in series with the probe of the vibration exciter (Figure 1), was used to adjust different contact forces: $0.3 \mathrm{~N}, 0.6 \mathrm{~N}, 1.2 \mathrm{~N}, 2.4 \mathrm{~N}, 4.8 \mathrm{~N}$, and $9.6 \mathrm{~N}$. This was done to cover an extensive range of contact forces. Previous pilot measurements showed that approximately $10 \mathrm{~N}$ was the upper limit, both from a practical point of view and for the wellbeing of the subjects. The contact force was continuously monitored and, if 
necessary, readjusted between individual measurements. The investigation started with the lowest contact force of $0.3 \mathrm{~N}$. To give the skin sufficient recovery time and to prevent accumulating effects, the resting times between the individual contact forces were also increased exponentially (from $30 \mathrm{~s}$ to $8 \mathrm{~min}$ ) to accommodate possible disadvantages of non-randomization.

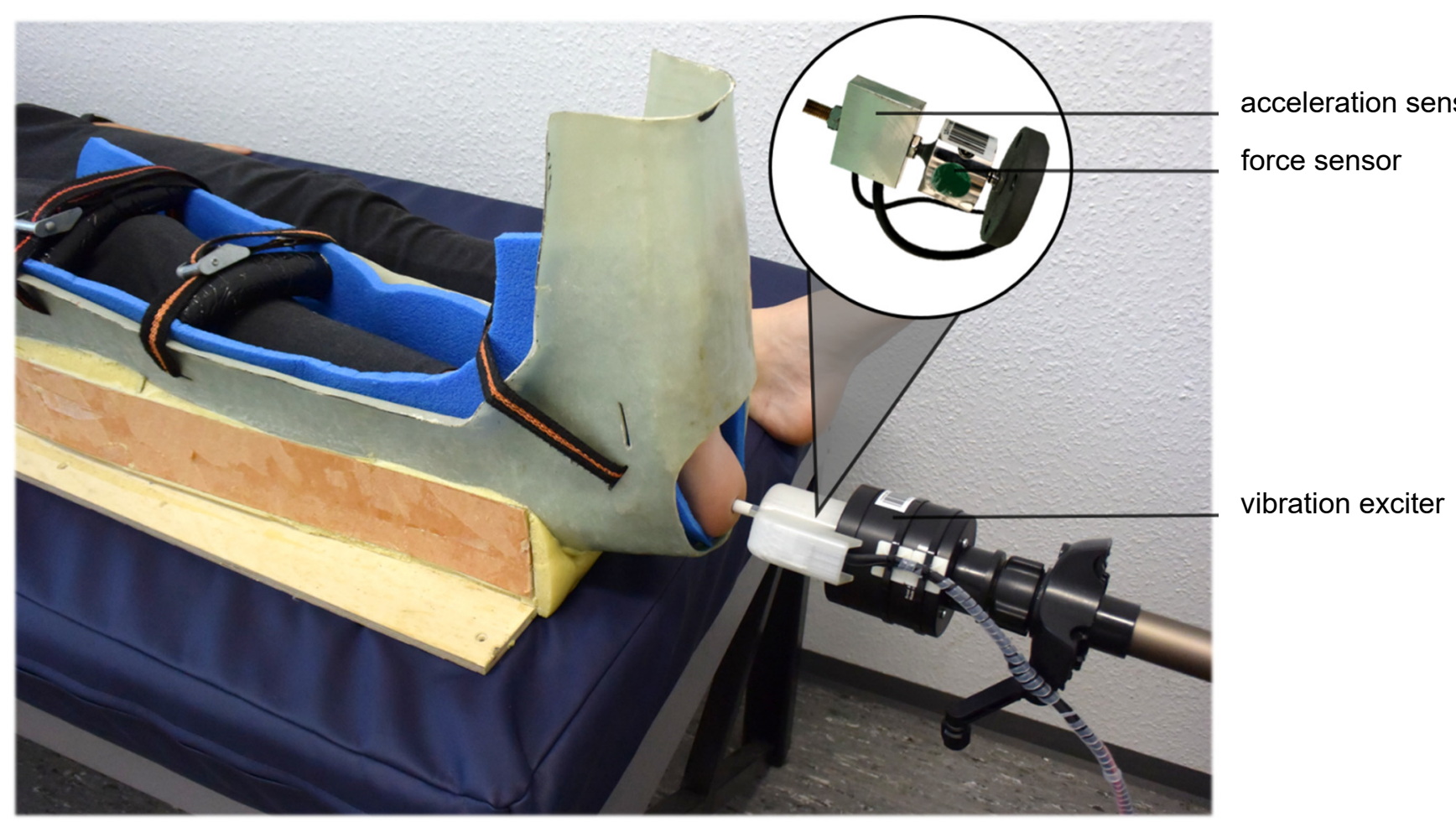

Figure 1. Measurement setup. The $7.8 \mathrm{~mm}$ diameter probe (area $\sim 48 \mathrm{~mm}^{2}$ ) of the modified vibration exciter placed perpendicularly at the plantar heel of the right foot. To keep the test person's foot as still as possible, the foot was strapped into a cushioned splint. The contact forces $(0.3 \mathrm{~N}, 0.6 \mathrm{~N}, 1.2 \mathrm{~N}, 2.4 \mathrm{~N}, 4.8 \mathrm{~N}$, and 9.6 N) were adjusted and continuously monitored using a force sensor. The amplitude of the vibration was measured directly in micrometers using an accelerometer.

VPTs were measured at the heel of the right foot at two different frequencies: $30 \mathrm{~Hz}$ and $200 \mathrm{~Hz}$. These two frequencies are considered ideal for measuring the vibration perception of Meissner and Pacinian corpuscles [6,7]. After a 10-min acclimation period, participants lay supine with their right foot fixed in a cushioned splint (Figure 1). VPTs were measured three times for each contact force using a self-written binary search method [15,22]. Participants had to press a button as soon as they felt a vibration. Starting with a sinusoidal vibration burst above the participants' individual thresholds ( $2 \mathrm{~s}$ duration followed by a 2-7 s pause), the program reduced or increased the stimulus intensity automatically, depending on whether the subject felt the last stimulus. The algorithm stopped four bursts after the first undetected stimulus. The mean of the last recognized and the last unperceived vibration stimuli was determined as VPT. A graphical visualization of the measurement algorithm can be found in Appendix A (Figure A1). If the subjects pressed the button more than twice while no stimulus was present, the measurement was repeated. Out of a total of 360 measurements, only four had to be repeated $(\sim 1 \%)$. A single VPT measurement took about $2 \mathrm{~min}$. The three measurements per contact force thus resulted in a duration of approximately $6 \mathrm{~min}$. The skin recovery time lasted a total of $15 \mathrm{~min}$ and $30 \mathrm{~s}$. Including acclimatization, test trials, and storing the VPTs, this resulted in a total duration of approximately one and a half hours per test subject. Therefore, the two different frequencies were measured on two different days to allow subjects to concentrate for as long as possible. Since two different mechanoreceptors were addressed by the selected frequencies, learning effects were not expected. 
Participants wore noise-cancelling headphones (QuietComfort 25 Acoustic Noise Cancelling headphones, Bose Corp., Framingham, MA, USA) to eliminate environmental noises. Temperature values of the foot were monitored using a non-contact infrared thermometer (UNI-T UT301C, Batronix GmbH \& Co. KG, Preetz, Germany).

The mean out of three VPT measurements per contact force condition was used for statistical analysis with R [27]. Data was checked for outliers, and the benefit of logarithmical transformation due to non-normal distribution was tested. After logarithmic transformation, the distribution of the data was still non-normal. The Aligned Rank Transform (ART) procedure was used to examine interaction effects [28]. A post hoc analysis was performed using interaction contrasts, looking at differences of differences [28].

\section{Results}

Plantar temperature was within acceptable ranges ( $30 \mathrm{~Hz}$ pre vs. post: $22.1 \pm 1.5 \mathrm{vs}$. $23.6 \pm 2.7 ; 200 \mathrm{~Hz}$ pre vs. post: $23.4 \pm 2.9$ vs. $24.2 \pm 2.4$ ) [12]. VPTs decreased at both frequencies with increasing contact forces (Table 1, Figures 2 and 3).

Table 1. Vibration perception thresholds $[\mu \mathrm{m}]$ for each contact force $(\mathrm{N})$ and frequency $(\mathrm{Hz})$.

\begin{tabular}{ccccccc}
\hline $\boldsymbol{n}=\mathbf{1 0}$ & $\mathbf{0 . 3} \mathbf{~ N}$ & $\mathbf{0 . 6} \mathbf{~ N}$ & $\mathbf{1 . 2} \mathbf{~ N}$ & $\mathbf{2 . 4} \mathbf{~ N}$ & $\mathbf{4 . 8 ~} \mathbf{~}$ & $\mathbf{9 . 6 ~ N}$ \\
\hline VPT 30 Hz $(\mu \mathrm{m})$ & $10.9 \pm 6.2$ & $9.3 \pm 5.3$ & $7.5 \pm 3.0$ & $6.4 \pm 4.5$ & $4.1 \pm 2.5$ & $3.9 \pm 2.5$ \\
VPT 200 Hz $(\mu \mathrm{m})$ & $1.8 \pm 2.8$ & $1.5 \pm 2.0$ & $1.2 \pm 1.6$ & $1.4 \pm 2.2$ & $0.8 \pm 0.9$ & $0.7 \pm 0.7$ \\
\hline Mean + SD of vibration perception thresholds (VPTs) & & &
\end{tabular}

Mean \pm SD of vibration perception thresholds (VPTs).
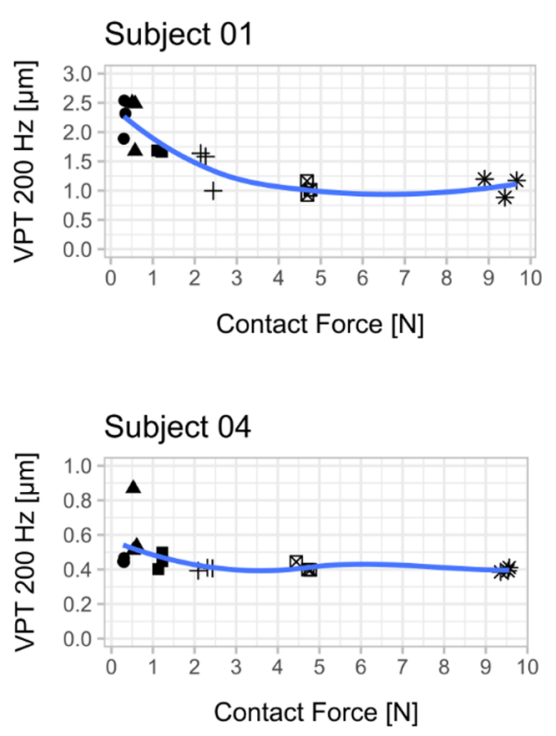
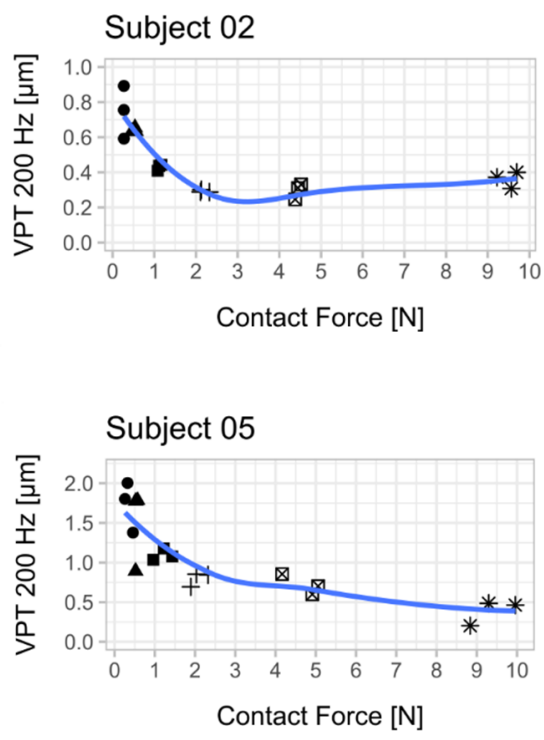

Figure 2. Cont.
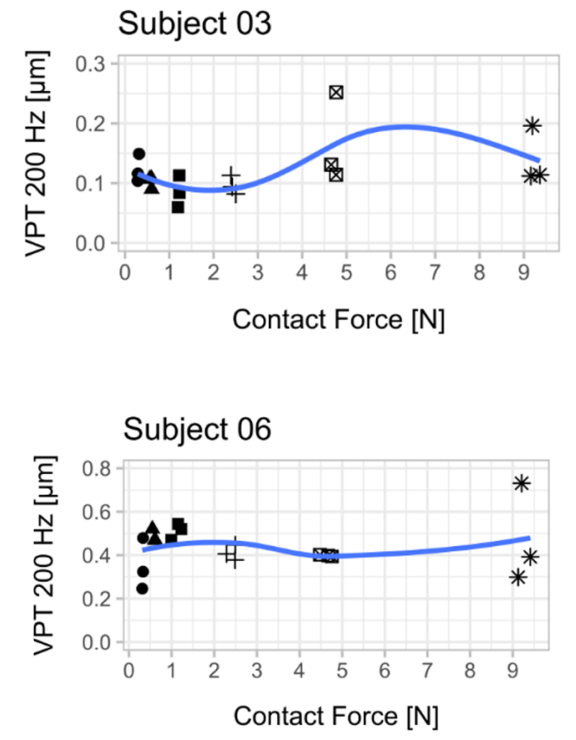

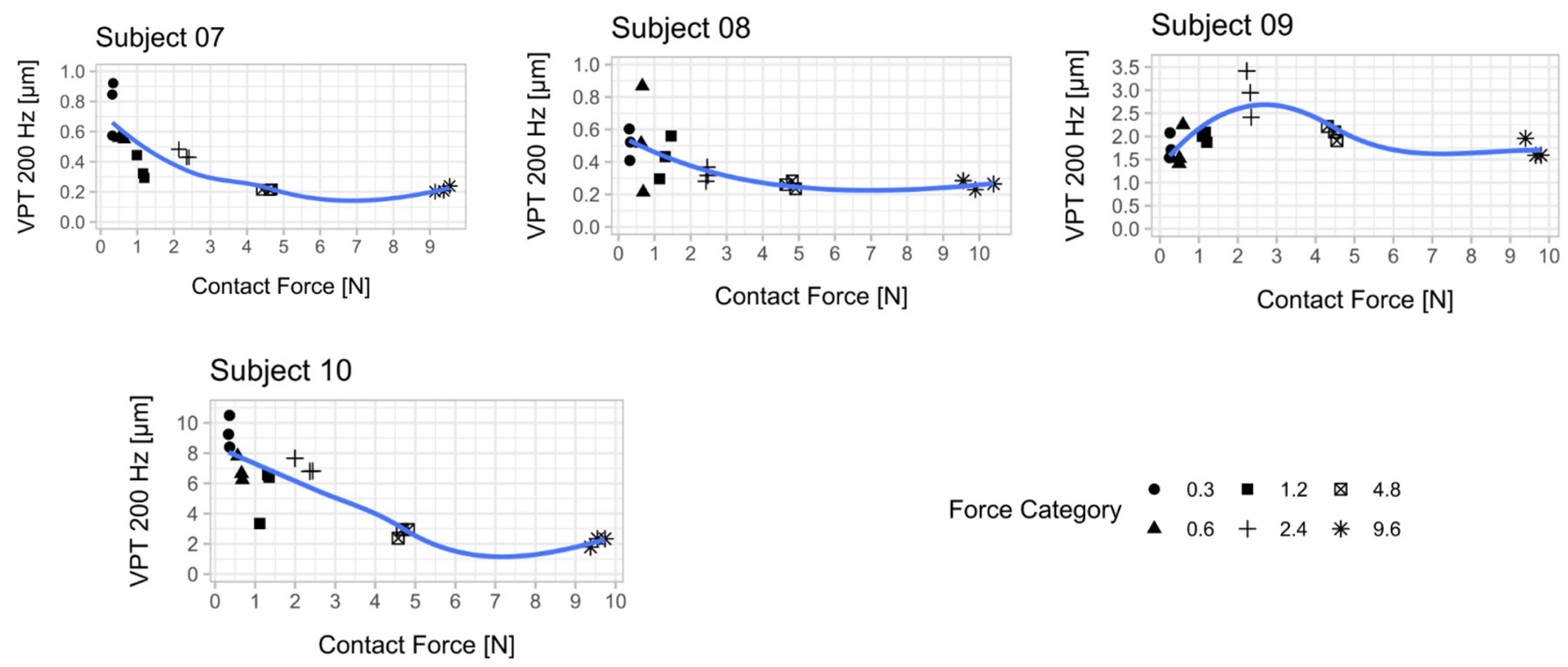

Force Category $\bullet \begin{array}{lllll}\bullet & 0.3 & \mathbf{0} & \otimes & 4.8\end{array}$

Figure 2. Relationship between vibration perception thresholds (VPT) at $200 \mathrm{~Hz}$ and contact force for each subject. Each scatter plot shows the three determined VPTs for each contact force condition. A smoothed conditional mean was added using the R function "geom_smooth ()" in combination with the argument "method = loess". Seven out of 10 subjects showed a reduction in VPT with increasing contact force. The mean from the respective three VPT measurements per contact force was used for statistical analysis (Figure 4). An attempt was made to establish a psychophysical relationship between the contact force and the perceived sensitivity across all subjects (Appendix B, Figure A2).

Subject 01

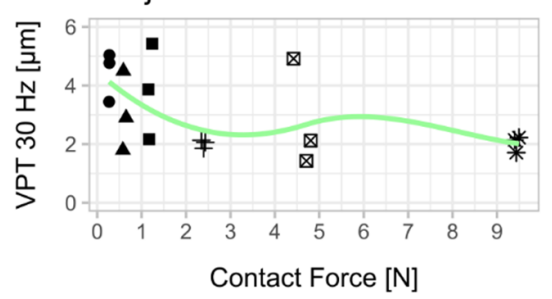

\section{Subject 04}

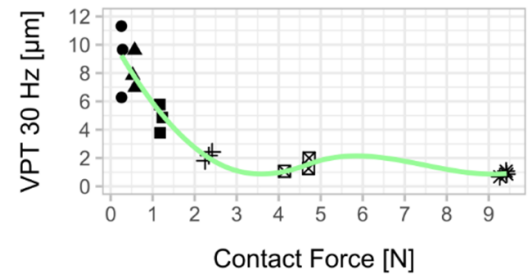

Subject 07

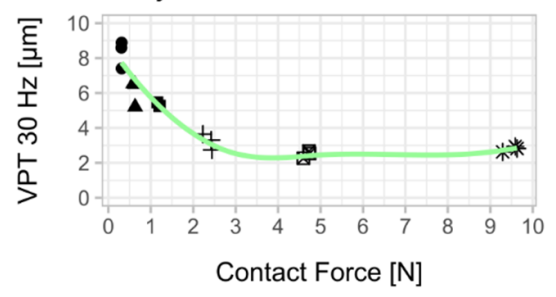

Subject 02

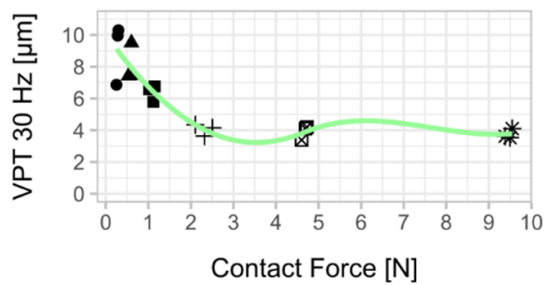

Subject 05

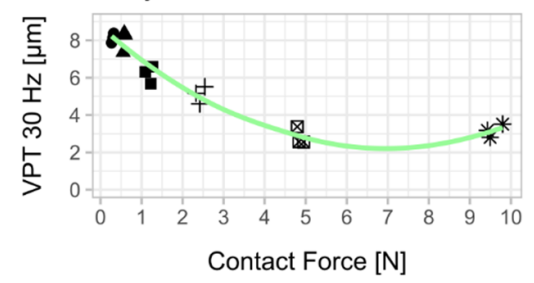

Subject 08

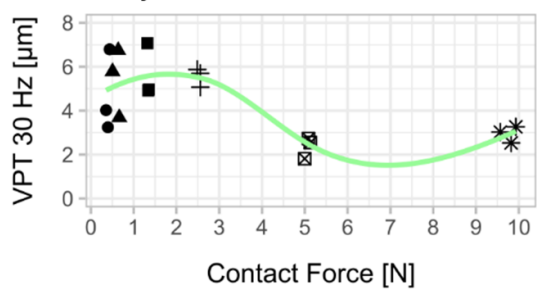

Figure 3. Cont.
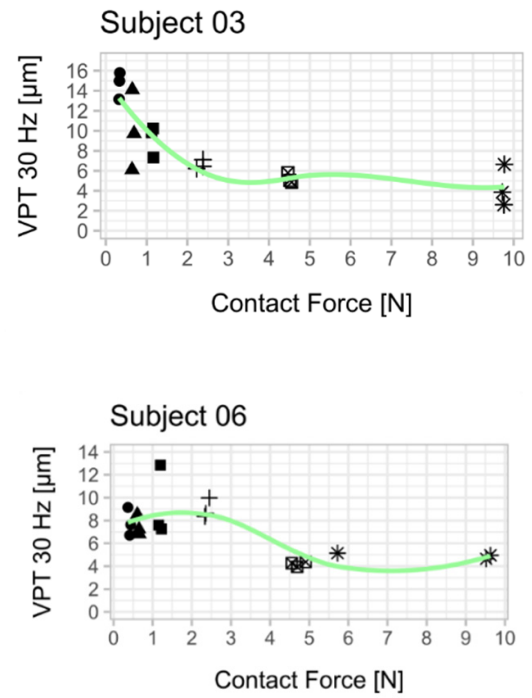

Subject 09

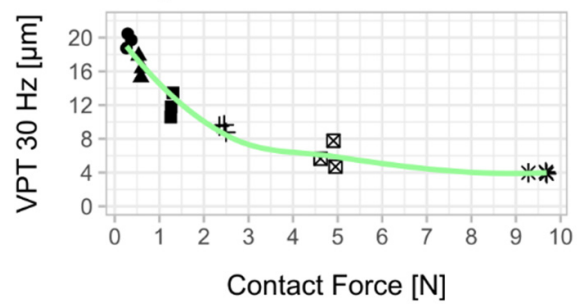




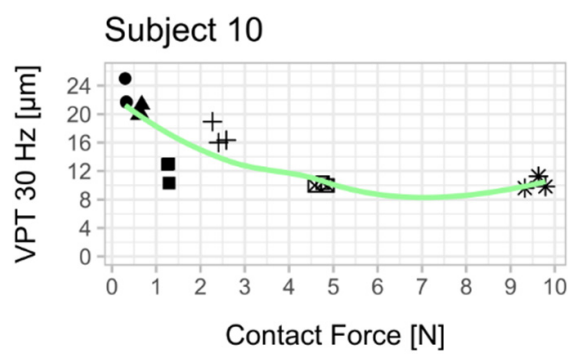

$\begin{array}{lllllll}\text { Force Category } & \bullet & 0.3 & \mathbf{\Delta} & 1.2 & \otimes & 4.8 \\ \mathbf{\Delta} & 0.6 & + & 2.4 & * & 9.6\end{array}$

Figure 3. Relationship between vibration perception thresholds (VPT) at $30 \mathrm{~Hz}$ and contact force for each subject. Each scatter plot shows the three determined VPTs for each contact force condition. A smoothed conditional mean was added using the R function "geom_smooth ()" in combination with the argument "method = loess". All 10 subjects showed a reduction in VPT with increasing contact force. The mean from the respective three VPT measurements per contact force was used for statistical analysis (Figure 4). An attempt was made to establish a psychophysical relationship between the contact force and the perceived sensitivity across all subjects (Appendix B, Figure A2).

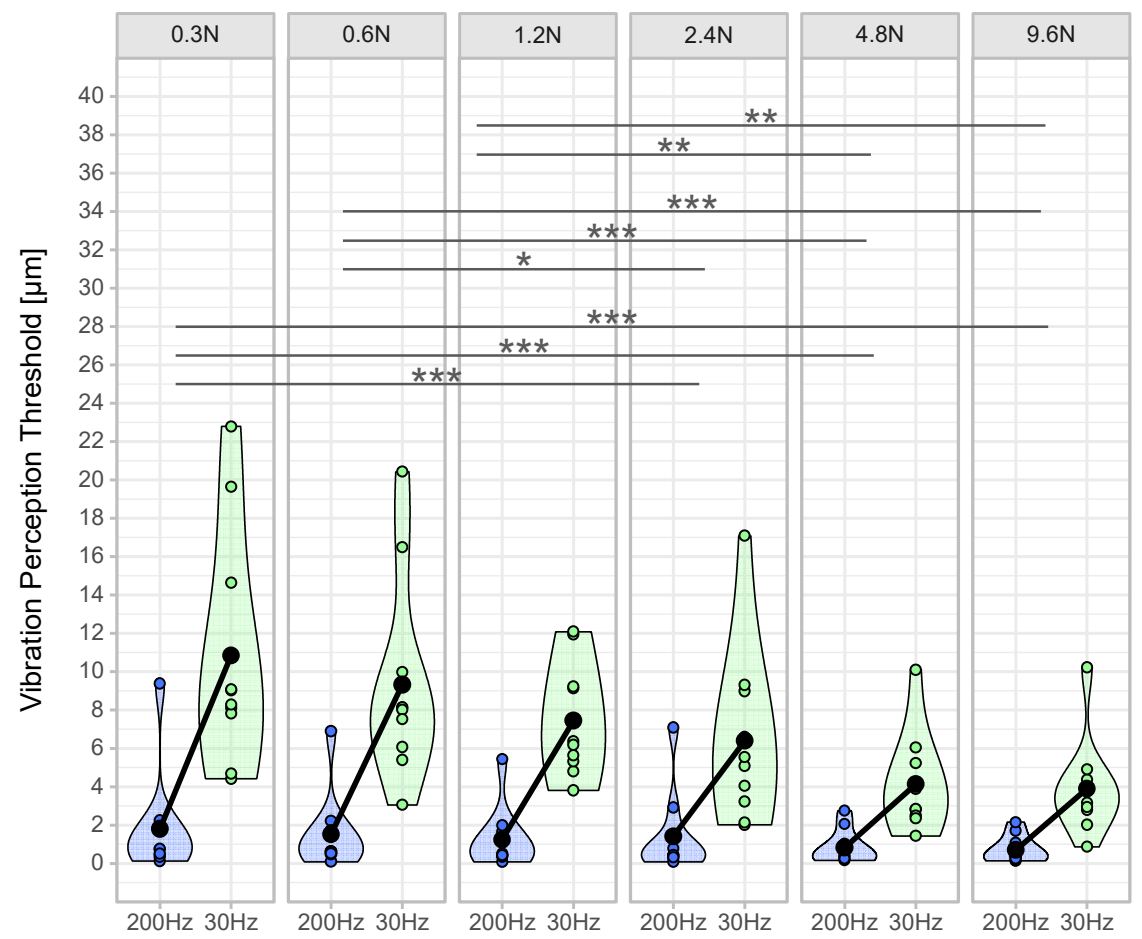

Figure 4. Vibration perception thresholds per contact force and frequency. The violin plots show the density of the distribution for the vibration perception thresholds (VPT) for the frequencies $200 \mathrm{~Hz}$ (blue) and $30 \mathrm{~Hz}$ (green) of the respective contact forces based on the width of the plot ( $n=10$ per contact force condition). The individual points within the violin plots represent the averaged VPT (mean out of three VPT measurements per contact force condition) of each subject. The black dot is the mean value of all subjects. The connecting line between the black dots represents the mean difference. Superscripted symbols represent significant interaction contrasts and differences of the differences $\left(* * * p<0.001,{ }^{* *} p<0.01,{ }^{*} p<0.05\right)$. 
A significant main effect was found for 'frequency', indicating lower thresholds (higher sensitivity) for $200 \mathrm{~Hz}$ measurements $\left(\mathrm{F}(1,99)=306.837, p<0.001, \eta_{\mathrm{p}}{ }^{2}=0.76\right)$. Furthermore, there was a significant main effect for 'contact force', meaning lower thresholds (higher sensitivity) with increased contact forces $\left(\mathrm{F}(5,99)=19.610, p<0.001, \eta_{\mathrm{p}}{ }^{2}=0.50\right)$. Additionally, a significant interaction effect was observed for 'frequency' and 'contact force', which means that increased contact force led to higher reductions in VPTs at $30 \mathrm{~Hz}$ compared to $200 \mathrm{~Hz}\left(\mathrm{~F}(5,99)=12.947, p<0.001, \eta_{\mathrm{p}}{ }^{2}=0.40\right)$.

Interaction contrasts (Figure 4) were found for the difference between VPTs at $200 \mathrm{~Hz}$ and $30 \mathrm{~Hz}$ in the contact force condition $0.3 \mathrm{~N}$ compared to the differences at $2.4 \mathrm{~N}, 4.8 \mathrm{~N}$, and $9.6 \mathrm{~N}$ (all $p<0.001)$. Further significant differences of differences were found between $0.6 \mathrm{~N}$ and $2.4 \mathrm{~N}(p=0.018), 4.8 \mathrm{~N}$, and $9.6 \mathrm{~N}$ (both $p<0.001)$ and between $1.2 \mathrm{~N}$ and $4.8 \mathrm{~N}$ $(p=0.005)$ and $9.6 \mathrm{~N}(p=0.001)$.

\section{Discussion}

The aim of the present study was to investigate the effects of increasing contact forces on VPTs of two different mechanoreceptors (Meissner and Pacinian corpuscles) in healthy young subjects. We hypothesized that greater contact forces lead to lower VPTs at both mechanoreceptors and, based on their anatomical location, that there is an interaction between sensor type and increasing contact force.

In accordance with the literature, we found a significant main effect for 'frequency', indicating lower thresholds for $200 \mathrm{~Hz}$ compared to $30 \mathrm{~Hz}$ [8,22]. Furthermore, we found a significant main effect for 'contact force', meaning that an increased contact force led to lower VPTs and, therefore, to better sensitivity. Furthermore, we found a significant interacting effect between 'frequency' and 'contact force', meaning that the influence of increasing contact force was different for Meissner than for Pacinian corpuscles. Figures 2 and 3 show a more pronounced decrease at $30 \mathrm{~Hz}$ than at $200 \mathrm{~Hz}$. Pairwise comparisons exhibited significant differences between lower $(0.3 \mathrm{~N}-1.2 \mathrm{~N})$ and higher contact forces $(2.4 \mathrm{~N}-9.6 \mathrm{~N})$ (Figure 4).

\subsection{Meissner Corpuscles}

Meissner corpuscles have circular receptive fields with several zones of maximal sensitivity [6]. This area of high sensitivity lies in the middle of the circular receptive field. Towards the periphery, the Meissner corpuscle is increasingly less sensitive [6]. The increasing pressure caused increased skin deformation, because the area of skin surrounding the probe also increased [29]. This may not only have led to a reduction in the distance between the stimulus and the perception hotspots, but also to a general increase in the number of Meissner corpuscles being addressed [29]. Additionally, increasing contact forces led to mechanical deformation of the non-neuronal components. In the Meissner corpuscles, force transmission through collagen fibers results in bending of the axon terminals [5]. This compression generates action potentials during stimulus onset [5]. High contact forces might have pre-bent axon terminals before the actual stimulus. Thus, it is possible that the low-frequency vibrations can be transmitted more directly to the axon and, thus, trigger action potentials more easily.

Furthermore, in the hallux, for example, Meissner corpuscles reach a density of approximately $10 / \mathrm{mm}^{2}$ [30]. Our probe stimulated a skin area of $\sim 48 \mathrm{~mm}^{2}$. However, more surrounding skin was indented by the probe at higher pressures, which might have increased the affected area. Furthermore, skin mechanics change due to compression. The compressed skin may transmit vibrations farther across the skin [1]. Thus, more Meissner corpuscles can be used for stimulus detection. Interestingly, Gu and Griffin [10] challenge the theory of the increasing number of responding Meissner corpuscles [10]. They tested the spatial summation for vibrotactile stimuli of Meissner and Pacinian corpuscles at the foot. They used different probe sizes (1-10 $\mathrm{mm}$ in diameter) and vibration frequencies of $20 \mathrm{~Hz}$ and $160 \mathrm{~Hz}$. They showed that the VPT decreased with increasing area only 
at a frequency of $160 \mathrm{~Hz}$ (representative for Pacinian corpuscles) [10]. Therefore, spatial summation only seems to occur at higher frequencies $[9,10]$.

In addition to our approach regarding perception hotspots described above, the synergistic cooperation of slowly adapting type I receptors (Merkel discs) and rapidly adapting receptors (Meissner corpuscles) may provide a second explanatory model. Meissner corpuscles are relatively insensitive to static forces and have a high sensitivity at low spatial resolutions [31]. On the other hand, Merkel discs have a low sensitivity at high spatial resolutions [31]. According to Abraira and Ginty [31], it is conceivable that Merkel discs and Meissner corpuscles act together to encode a more complete picture of tactile space [31]. Merkel discs react to mechanical forces on the skin with a persistent and graded dynamic, followed by 'bursting' at irregular intervals, which correlates linearly with penetration depth [31,32]. We know that Merkel disc receptors also encode low frequency vibrations (5$15 \mathrm{~Hz}$ ) and that the transition between the frequency coding of the receptors overlaps [33]. Therefore, the increasing contact force could have led to an increased synergistic response behavior of Merkel discs. This synergistic interaction could have led to the increased sensitivity measured during the $30 \mathrm{~Hz}$ condition.

Based on this synergistic interaction of these two mechanoreceptors, the increased sensitivity with increasing contact forces may also be attributed to contrast enhancement. Due to the receptor density and the overlapping receptive fields, sensory information is mediated simultaneously by several receptors [34]. As a result, the functional organization of the sensory processing networks is hierarchical [34]. Laterally inhibiting interneurons reduce or inhibit the excitation of weak signals at the receptors' first interconnection level due to the activity in the neurons with strong signals [35]. As already mentioned, more receptors may be involved in stimulus detection with increasing contact force. To enable the neural network to precisely identify the stimulus source, i.e., the probe, adjacent weaker stimuli stemming from skin deformation may be more severely inhibited than for lower contact forces. At the same time, the signal of the strongly activated receptors directly under the probe would be amplified even more, so that the original stimulus (the vibration) could be perceived better.

\subsection{Pacinian Corpuscles}

As already mentioned, the improvement in sensitivity of the Pacinian corpuscles with increasing contact force seems to be the result of spatial summation [10]. While Gu and Griffin [10] used different probe sizes and vibration frequencies, Kekoni et al. [9] described another point which may have led to spatial summation in our study. They used the same vibration exciter with a similar measurement methodology [9]. By directly applying the probe of the vibration exciter to the measurement site, the vibration stimulus can spread to surrounding skin areas [9]. Supported by the possibility of changing skin characteristics from increasing compression and the high sensitivity of the Pacinian corpuscles, these residual vibrations, depending on their intensity, can also cause reactions in surrounding Pacinian corpuscles [36]. The altered and far-reaching proliferation of vibrations with altered contact forces of the probe represents a possible reason for the improving sensitivity of the Pacinian corpuscles. The smallest residual vibration may already lead to the excitation of surrounding Pacinian corpuscles. This is supported by the assumption that mechanical skin properties and the reaction of the Pacinian corpuscles may act together due to the skin's own resonance and the optimal sensitivity of the Pacinian corpuscles [36].

Additionally, Pacinian corpuscles are not only located in the dermis, but also in the periosteum or interosseous membrane [32,37]. As the contact force increases, the heel fat pad is compressed, and the probe and calcaneus come closer together. The vibration stimulus may therefore be transmitted to the Pacinian corpuscles located in the periosteum/interosseous membrane and, thus, possibly have been the reason for the improved sensitivity of the Pacinian corpuscles. 


\subsection{General Aspects and Limitations}

Many of our discursive approaches were interpretive, based on the interaction between mechanoreceptors, stimulus conduction, and stimulus processing. Unfortunately, we were limited by our technical possibilities and could only measure the outcome of mechanoreceptor stimulation in terms of VPTs. Using microneurography, including stimulus conduction and EEG-measurements, may provide information on stimulus processing. Furthermore, generalization of our discursive approaches is limited due to the small number of subjects, only one measured anatomical location, and one probe size. Based on a different receptor distribution and differences in the mechanical skin properties $[1,38]$, an inclusion of further anatomical locations on the sole of the foot (e.g., first metatarsal head or big toe) and different probe sizes would be useful in further studies. An increase in the number of subjects is also conceivable. However, in sensory measurements, the neuronal responses that arise from stimulating receptors can be influenced by attention, cognitive processes, and other behavior patterns of the perceiver [39]. The success of sensory measurements depends to a large extent on the cooperation of the subject. To maintain high levels of concentration, the breaks described in the methods section for the skin to recover were also used as time for subjects to relax. In addition, the measurements at the two different frequencies were distributed over two days to ensure the active participation of the subjects at all times.

Based on our results, we were able to establish a relationship between VPTs and contact forces considering different measurement frequencies. If we disregard the two highest contact forces tested in this study $(4.8 \mathrm{~N}$ and $9.6 \mathrm{~N})$, the lowest variability for determining VPTs was seen at $1.2 \mathrm{~N}$ (Figure 4). The highest contact forces led to strong skin deformations, which could influence the response behavior of the mechanoreceptors and were unpleasant for the test subjects.

Author Contributions: C.Z., B.W. and T.L.M. participated in the design of the study; C.Z. and B.W. performed the experiments; C.Z. analyzed the data and designed figures; C.Z. and B.W. drafted the manuscript; C.Z., B.W. and T.L.M. edited and revised the manuscript and data analysis. All authors have read and agreed to the published version of the manuscript.

Funding: C.Z. would like to thank the Sächsische Aufbaubank (SAB) for providing scholarship funding from the European Social Fund (ESF) and the Free State of Saxony. The publication of this article was funded by Chemnitz University of Technology.

Institutional Review Board Statement: The study was conducted according to the guidelines of the Declaration of Helsinki. The measurement system and methodology were approved by the Ethics Committee of the Faculty of Behavioural and Social Sciences of the corresponding university in a similar study of our working group (V-277-17-DS-KUS/WUS-22062018).

Informed Consent Statement: Informed consent was obtained from all subjects involved in the study.

Data Availability Statement: The data presented in this study are available on request from the corresponding author. The data are not publicly available due to further analyses.

Acknowledgments: The authors would like to thank Lisa Peterson for her linguistic assistance with the manuscript, as well as Ralph Dörfler, Philip Schulze, and Mirco Kaden for their technical support.

Conflicts of Interest: The authors declare no conflict of interest.

\section{Appendix A}

In the following, the measurement algorithm of a measurement trial to determine the VPT is visualized (Figure A1). The measurement algorithm adjusts the vibration amplitude according to the subjects' perception. The vibration frequency $(200 \mathrm{~Hz}$ or $30 \mathrm{~Hz})$ remains constant during a measurement. 


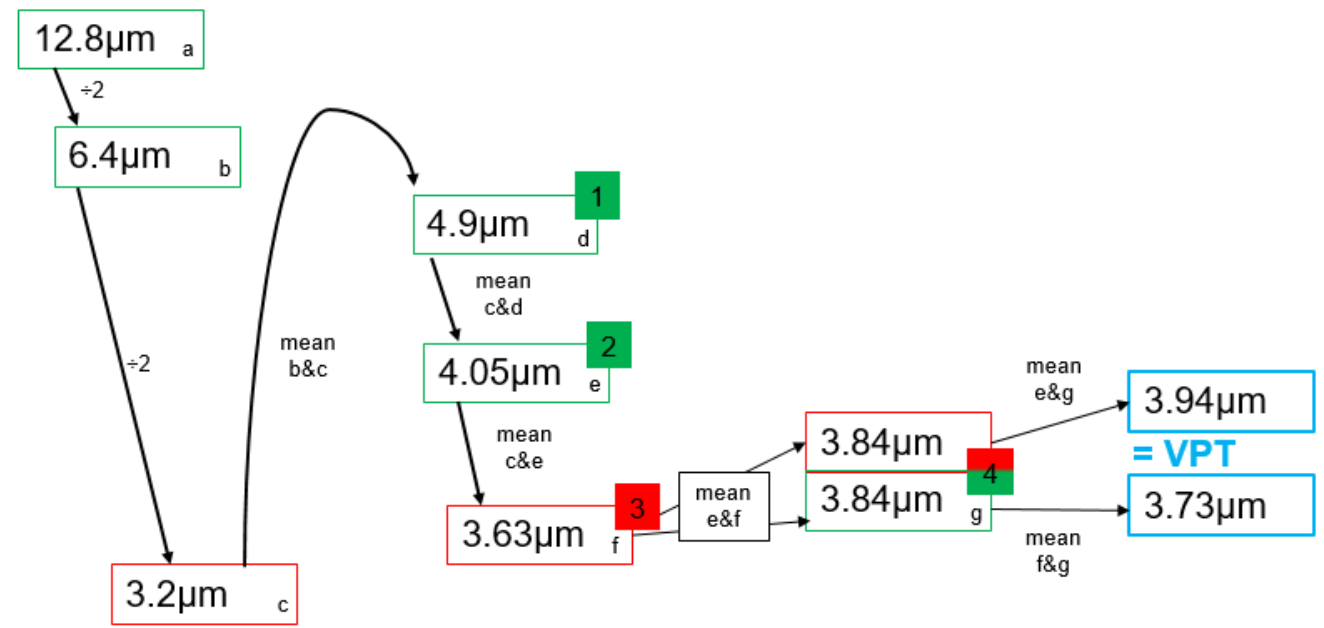

\section{burst detected burst not detected}

Figure A1. Exemplary procedure for determining VPT. The algorithm is started by the examiner with a vibration burst above the participants' individual threshold (a). The subject signals the perception of the initial stimulus by pressing a button. The algorithm then automatically halves the amplitude of the next stimulus to be tested (b) until the first vibration can no longer be perceived (c). The algorithm then averages the last perceived stimulus (b) and the last stimulus that was not felt (c) and continues determining the VPT using this averaged amplitude (d). After one vibration stimulus is not felt (c), the algorithm automatically tests four more stimuli according to the procedure just described (d-g). VPT is then the mean of the last recognized (e or $\mathbf{g}$ ) and the last unperceived ( $\mathbf{f}$ or $\mathbf{g}$ ) vibration stimulus.

\section{Appendix B}

Both mechanoreceptors have one common reaction to increasing contact forces: a doubling of the contact force does not lead to a vibration stimulus that is perceived twice as well. We summarized the psychophysical relationship in Figure A2. To create a sensation variable on the $y$-axis, the VPT values were multiplied by -1 . This gave us the perceived sensitivity in arbitrary units (a. u.). The three VPTs obtained for each contact force condition were summarized using the median for each subject.

\section{$200 \mathrm{~Hz}$}

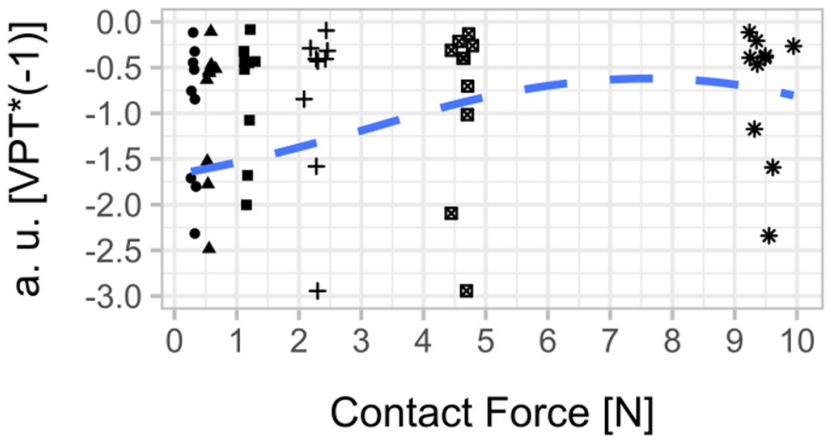

\section{$30 \mathrm{~Hz}$}

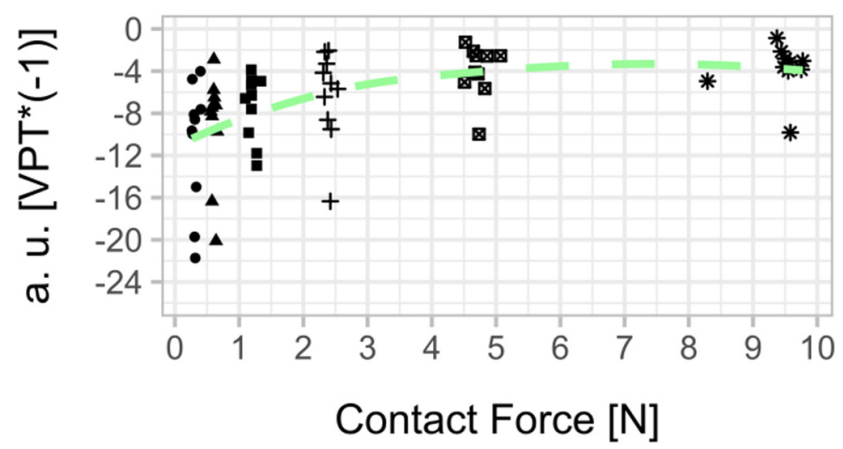

Contact Force $[\mathrm{N}]$

Force Category

- 0.3 - 1.2 凶 4.8
\ $0.6+2.4$ * 9.6

Figure A2. Psychophysical relationship between contact force and perceived sensitivity [VPT*(-1)] in arbitrary units (a. u.) at $200 \mathrm{~Hz}$ and $30 \mathrm{~Hz}$. The median was calculated for the three determined vibration perception thresholds (VPT) for each contact force condition per subjects. Thus, the scatter plots represent the whole sample size $(n=10)$. A smoothed conditional mean was added using the R function "geom_smooth ()" in combination with the argument "method = loess". 


\section{References}

1. Holowka, N.B.; Wynands, B.; Drechsel, T.J.; Yegian, A.K.; Tobolsky, V.A.; Okutoyi, P.; Mang'eni Ojiambo, R.; Haile, D.W.; Sigei, T.K.; Zippenfennig, C.; et al. Foot callus thickness does not trade off protection for tactile sensitivity during walking. Nature 2019, 571, 261-264. [CrossRef] [PubMed]

2. Prätorius, B.; Kimmeskamp, S.; Milani, T.L. The sensitivity of the sole of the foot in patients with Morbus Parkinson. Neurosci. Lett. 2003, 346, 173-176. [CrossRef]

3. Simmons, R.W.; Richardson, C.; Pozos, R. Postural stability of diabetic patients with and without cutaneous sensory deficit in the foot. Diabetes Res. Clin. Pract. 1997, 36, 153-160. [CrossRef]

4. Garrow, A.P.; Boulton, A.J.M. Vibration perception threshold-A valuable assessment of neural dysfunction in people with diabetes. Diabetes. Metab. Res. Rev. 2006, 22, 411-419. [CrossRef] [PubMed]

5. Zimmerman, A.; Bai, L.; Ginty, D.D. The gentle touch receptors of mammalian skin. Science 2014, 346, 950-954. [CrossRef] [PubMed]

6. Johansson, R.S.; Vallbo, Å.B. Tactile sensory coding in the glabrous skin of the human hand. Trends Neurosci. 1983, 6, 27-32. [CrossRef]

7. Johansson, R.S.; Landstro “m, U.; Lundstro“m, R. Responses of mechanoreceptive afferent units in the glabrous skin of the human hand to sinusoidal skin displacements. Brain Res. 1982, 244, 17-25. [CrossRef]

8. Wells, C.; Ward, L.M.; Chua, R.; Inglis, J.T. Regional Variation and Changes With Ageing in Vibrotactile Sensitivity in the Human Footsole. J. Gerontol. Ser. A Biol. Sci. Med. Sci. 2003, 58, B680-B686. [CrossRef] [PubMed]

9. Kekoni, J.; Hämäläinen, H.; Rautio, J.; Tukeva, T. Mechanical sensibility of the sole of the foot determined with vibratory stimuli of varying frequency. Exp. Brain Res. 1989, 78, 419-424. [CrossRef] [PubMed]

10. Gu, C.; Griffin, M.J. Spatial summation of vibrotactile sensations at the foot. Med. Eng. Phys. 2013, 35, 1221-1227. [CrossRef]

11. Strzalkowski, N.D.J.; Triano, J.J.; Lam, C.K.; Templeton, C.A.; Bent, L.R. Thresholds of skin sensitivity are partially influenced by mechanical properties of the skin on the foot sole. Physiol. Rep. 2015, 3. [CrossRef]

12. Schlee, G.; Sterzing, T.; Milani, T.L. Foot sole skin temperature affects plantar foot sensitivity. Clin. Neurophysiol. 2009, 120, 1548-1551. [CrossRef]

13. Hilz, M.J.; Axelrod, F.B.; Hermann, K.; Haertl, U.; Duetsch, M.; Neundörfer, B. Normative values of vibratory perception in 530 children, juveniles and adults aged 3-79 years. J. Neurol. Sci. 1998, 159, 219-225. [CrossRef]

14. Peters, R.M.; McKeown, M.D.; Carpenter, M.G.; Inglis, J.T. Losing touch: Age-related changes in plantar skin sensitivity, lower limb cutaneous reflex strength, and postural stability in older adults. J. Neurophysiol. 2016, 116, 1848-1858. [CrossRef] [PubMed]

15. Perry, S.D. Evaluation of age-related plantar-surface insensitivity and onset age of advanced insensitivity in older adults using vibratory and touch sensation tests. Neurosci. Lett. 2006, 392, 62-67. [CrossRef] [PubMed]

16. Cohen, L.H.; Lindley, S.B. Studies in Vibratory Sensibility. Am. J. Psychol. 1938, 51, 44. [CrossRef]

17. Cassella, J.P.; Ashford, R.L.; Kavanagh-Sharp, V. Effect of applied pressure in the determination of vibration sensitivity using the Neurothesiometer. Foot 2000, 10, 27-30. [CrossRef]

18. Lowenthal, L.M.; Derek, T.; Hockaday, R. Vibration Sensory Thresholds Depend On Pressure of Applied Stimulus. Diabetes Care 1987, 10, 100-102. [CrossRef]

19. Hagander, L.G.; Midani, H.A.; Kuskowski, M.A.; Parry, G.J. Quantitative sensory testing: Effect of site and pressure on vibration thresholds. Clin. Neurophysiol. 2000, 111, 1066-1069. [CrossRef]

20. Gregg, E.C. Absolute Measurement of the Vibratory Threshold. Arch. Neurol. Psychiatry 1951, 66, 403. [CrossRef]

21. Era, P.; Hanninen, V. The effects of intensity, frequency, static load, and shore hardness on different parameters in vibration sensitivity measurements. J. Neurol. Neurosurg. Psychiatry 1987, 50, 465-470. [CrossRef]

22. Mildren, R.L.; Strzalkowski, N.D.J.; Bent, L.R. Foot sole skin vibration perceptual thresholds are elevated in a standing posture compared to sitting. Gait Posture 2016, 43, 87-92. [CrossRef]

23. Germano, A.M.C.; Schmidt, D.; Schlee, G.; Milani, T.L. Plantar sensory vibration thresholds are not influenced by body position. Cogent Med. 2016, 3, 1238600. [CrossRef]

24. Gu, C.; Griffin, M.J. Vibrotactile perception thresholds at the sole of the foot: Effects of contact force and probe indentation. Med. Eng. Phys. 2012, 34, 447-452. [CrossRef] [PubMed]

25. Schmidt, D.; Schlee, G.; Germano, A.M.C.; Milani, T.L. Larger contactor area increases low-frequency vibratory sensitivity in hairy skin. PeerJ 2020, 2020, 1-13. [CrossRef] [PubMed]

26. Zippenfennig, C.; Niklaus, L.; Karger, K.; Milani, T.L. Subliminal electrical and mechanical stimulation does not improve foot sensitivity in healthy elderly subjects. Clin. Neurophysiol. Pract. 2018, 3, 151-158. [CrossRef] [PubMed]

27. R Core Team. R: A Language and Environment for Statistical Computing; R Foundation for Statistical Computing: Vienna, Austria, 2018; Available online: https:/ / www.R-project.org/ (accessed on 12 July 2021).

28. Wobbrock, J.O.; Findlater, L.; Gergle, D.; Higgins, J.J. The aligned rank transform for nonparametric factorial analyses using only anova procedures. In Proceedings of the 2011 Annual Conference on Human Factors in Computing Systems-CHI '11, Vancouver, BC, Canada, 7-12 May 2011; ACM Press: New York, NY, USA, 2011; p. 143.

29. Rhoades, R.A.; Pflanzer, R. Human Physiology, 4th ed.; Thomson: Stamford, CT, USA, 2003.

30. Bolton, C.F.; Winkelmann, R.K.; Dyck, P.J. A quantitative study of Meissner's corpuscles in man. Neurology 1966, 16. [CrossRef]

31. Abraira, V.E.; Ginty, D.D. The sensory neurons of touch. Neuron 2013, 79, 618-639. [CrossRef] 
32. Rowe, M.; Tracey, D.; Mahns, D.; Sahai, V.; Ivanusic, J. Mechanosensory Perception: Are There Contributions From BoneAssociated Receptors? Clin. Exp. Pharmacol. Physiol. 2005, 32, 100-108. [CrossRef]

33. Alzheimer, C. Somatoviszerale Sensibilität. In Physiologie: Mit 92 Tabellen; Elsevier: München, Germany, 2008 ; pp. 50-67.

34. Gardner, E.P.; Martin, J.H. Coding of Sensory Information. In Principles of Neural Science; McGraw-Hill: New York, NY, USA, 2000.

35. Rösler, F. Psychophysiologie der Kognition. Eine Einführung in die Kognitive Neurowissenschaft; Spektrum Akademischer Verlag: Heidelberg, Germany, 2011; ISBN 978-3-8274-2598-0.

36. Manfredi, L.R.; Baker, A.T.; Elias, D.O.; Dammann, J.F.; Zielinski, M.C.; Polashock, V.S.; Bensmaia, S.J. The Effect of Surface Wave Propagation on Neural Responses to Vibration in Primate Glabrous Skin. PLoS ONE 2012, 7, e31203. [CrossRef]

37. Fleming, M.S.; Luo, W. The anatomy, function, and development of mammalian A $\beta$ low-threshold mechanoreceptors. Front. Biol. 2013, 8, 408-420. [CrossRef] [PubMed]

38. Strzalkowski, N.D.J.; Peters, R.M.; Inglis, J.T.; Bent, L.R. Cutaneous afferent innervation of the human foot sole: What can we learn from single-unit recordings? J. Neurophysiol. 2018, 120, 1233-1246. [CrossRef] [PubMed]

39. Goldstein, E.B. Wahrnehmungspsychologie, 9th ed.; Gegenfurtner, K., Ed.; Springer: Berlin/Heidelberg, Germany, 2015; ISBN 978-3642-55073-7. 